Sharif University of Technology
Scientia Iranica
Transactions E: Industrial Engineering
http://scientiairanica.sharif.edu
IRAN I CA

\title{
Optimizing the number of outbound doors in the crossdock based on a new queuing system with the assumption of beta arrival time
}

\author{
A. Motaghedi-Larijani and M. Aminnayeri* \\ Department of Industrial Engineering \& Management Systems, Amirkabir University of Technology, Tehran, P.O. Box 1591634311, \\ Iran.
}

Received 22 February 2016; received in revised form 18 February 2017; accepted 22 April 2017

\section{KEYWORDS \\ Crossdock; \\ Queuing system; \\ Non-stationary; \\ Order statistics; \\ Conditional \\ probability.}

\begin{abstract}
Crossdocking is one of the supply chain strategies that can reduce costs of transportation and inventory. Many studies on the problem of crossdocking have been conducted with respect to various characteristics of crossdocks. In this paper, a queuing model is proposed in order to optimize the number of outbound doors based on minimizing the total costs, including the costs of adding a new outbound door and the expected waiting time of customers. The total number of trucks arriving for service is constant. Trucks arrive at outbound doors of the crossdock within a specified time window. Arrival times of trucks follow a beta distribution, and customers are served based on First-In, First-Out policy (FIFO). Since the total number of customers as well as the time of arrivals are finite, the steady state distribution is inapplicable to the long run of the system. Instead, the total expected waiting time is calculated based on conditional joint probabilities, order statistics along with the Bayes theorem.

(C) 2018 Sharif University of Technology. All rights reserved.
\end{abstract}

\section{Introduction}

In traditional distribution systems, warehouses are used to deliver goods from manufacturers to customers. Products are first received and, then, stored. When a customer requests an item, products are selected from the warehouse and shipped to the customers' destinations. Unlike traditional warehouses, crossdocking is an approach to eliminating storage and order picking operations. It would reduce the supply chain cost [1]. Crossdocking reduces response time, inventory, and transportation costs.

\footnotetext{
*. Corresponding author. Tel.: +982164545335; Fax: +982164545335

E-mail addresses: larijani@aut.ac.ir (A.

Motaghedi-Larijani); mjnayeri@aut.ac.ir (M. Aminnayeri)
}

doi: $10.24200 /$ sci.2017.4452
For the first time, Walmart replaced the warehouse with crossdocking. Products are delivered to a crossdock from suppliers or manufacturers, and consolidated products are delivered to customers [2]. Based on the crossdocking approach, there are two types of trucks: inbounds and outbounds. Inbound trucks come to the crossdock and unload the products. Products and shipments are sorted based on their characteristics and consolidated in the crossdock. Then, products are moved to outbound doors by an internal transportation facility. Finally, outbound trucks go to the crossdock to load the combined products and deliver them to customers.

Although the crossdocking approach reduces warehousing cost, elimination of stock levels is unavoidable. When a product arrives at the shipping dock, it is sometimes impossible to load onto the outbound truck immediately. Therefore, the product is stored in the temporary storage for less than $24 \mathrm{~h}$, 
until the appropriate outbound truck comes into the shipping dock. Some studies on crossdocking consider temporary storage such as [3-9].

A crossdocking facility has a number of dock doors, where trucks can load or unload goods. Van Belle et al. [1] classified crossdocks by physical, operational, and flow characteristics and described each of them. They also reviewed studies on the decision problems solved by the crossdocking approach. These problems are related to strategic, tactical, and operational decision-making levels. Based on their classification, layout design of a crossdock is one of the problems that is categorized as a strategic decision problem. The common shape of crossdocks is similar to I, L, U, T, and Bartholdi and Gue [10] studied the best shape of crossdocks. They concluded that the best shape of a crossdock depends on the size of the facility and pattern of freight flows inside. They considered the average travel distance to approximate the total travel cost across the dock and took it to estimate the variable labor cost to move freight through the facility.

Hauser and Chung [11] studied the lane layout optimization with the crossdocking to reduce the workload of team members in crossdocks. They believed that layout optimization of a crossdock minimizes the workload and can reduce a shorter overall lead-time. In order to minimize handling and waiting times, Vis and Roodbergen [12] proposed a new problem to design the storage area for crossdocking and presented a dynamic methodology. The methodology led to the selection of control policies concerning both routing and storage assignment.

Determining the total number of doors is the first and most important physical characteristic of a crossdock [13]. The number of outbound doors equals that of destination in some of the existing crossdocks. Facility setup cost depends on its size. The size of a crossdock relates to the number of doors. In some cases, due to the setup cost and size limitation of the crossdock, the number of outbound doors is not equal to that of destination. Lim et al. [14] considered the number of trucks that exceeds the number of docks available. They studied truck assignment problem with time windows and capacity constraint in transshipment network through crossdocks to minimize the total shipping distances.

Increasing the number of doors increases the setup cost of facility as well as imposes the labor costs. Labor costs correspond to the loading or unloading process and traveling of freight. To the best of our knowledge, no studies that focus on determining the optimum number of outbound doors, considering the mentioned costs totally.

Various optimization problems are proposed for crossdocks to improve their performances. These problems are related to strategic, tactical, and operational decision-making levels. Some researches of crossdocking optimization are focused on the scheduling of trucks. Dock assignment to trucks is an important decision-making task at crossdocks. Gelareh et al. [15] studied the dock assignment problem of trucks with an operational time constraint. They assumed that $n$ trucks arrive at the crossdock during the time window.

The crossdock scheduling problem focuses on determining the assignment and order of service of the incoming and outgoing trucks to the inbound and outbound doors. Crossdock scheduling closely relates to the classic machine scheduling. Boysen and Fliedner [16] introduced a classification of truck scheduling problems and reviewed all papers with deterministic arrival times of trucks. There are many studies on the crossdock scheduling, assuming that trucks are ready at start times such as [3-5].

Time window assumption of the arrival times of trucks is more realistic, rather than the exact time [17]. Time windows for delivery and pickup services in crossdocking are common constraints. Manufacturers and customers impose time window constraints on crossdocks [18]. There is vast literature available on crossdocking optimization problems that consider time window constraints $[14,17-20]$.

Most of the studies have only considered deterministic information about crossdocking; hence, they do not consider any uncertainties. This simplifying assumption is not applicable to the real world. Walha et al. [21] reviewed the existing literature on the crossdocking under uncertainty. They classified research based on three types of uncertainties: external uncertainty, internal uncertainty, and the combination of both types. The factors coming from outside of the crossdock area give rise to external uncertainties such as truck arrival times, number of inbound trailers, and the freight flow/content of truck.

Most of the crossdock scheduling problems assume deterministic truck arrival times. This assumption is unrealistic as truck arrivals are subject to uncertainties due to traffic congestion, weather conditions, etc. [22]. Konur and Golias [23] studied the scheduling of inbound trucks at the inbound doors of a crossdock facility under the uncertainty of truck arrival times in order to minimize the total service time. They considered that the arrival time of an inbound truck is unknown, and the only available information is about the lower and upper bounds of any inbound truck's arrival time. They used three approaches to determining a scheduling strategy: deterministic, pessimistic, and optimistic approaches.

Larbi et al. [24] studied the crossdock scheduling problem in a single receiving crossdock and a single shipping door crossdock under three situations of full, partial, and no information on the freight flow and arrival time of inbound trucks. Their objective was 
to find the best schedule for the transshipment operations, which minimized the total additional handling and the truck replacement costs. The uncertainty of arrival times of trucks is an important subject of crossdocking problems that is an effect of optimization problems. For further information, see the following references [25-27].

Since almost all problems are solved in the literature within the assumption of certain parameters, it is necessary to look at the problems with uncertain parameters. The impact of uncertainty can raise a new optimization problem that relates to queueing systems. Since the outbound trucks randomly arrive at a crossdock to load products within the time window, the classic scheduling of trucks is inapplicable. Therefore, trucks should be loaded by the first-in, firstout rule. According to the queuing system, trucks and outbounds are as customers and servers.

Queueing problems at a service facility are common problems in the transportation and logistics industry. The waiting time of trucks, in the queue, imposes some costs on the supply chain system.

Outbound trucks arrive at a crossdock to be loaded at random within a time window. They will be served in a constant time. It is assumed that the number of doors is the decision variable. There are two possibilities for trucks when arriving at the outbound door:

(I) At least one door is empty and trucks are able to start loading;

(II) All doors are busy and trucks have to wait for a server to be idle to be served.

The distribution of the arrival time is beta or uniform. Other distributions can be done in the same way. The number of outbound trucks arriving for the service is fixed in the given time window.

A fixed number of customers arrive at the system in a fixed time window. These features make our model different from an ordinary queuing model such as $M / M / 1, M / G / 1$, and $G / G / 1$. Actually, our model is named a finite queuing model. Hence, no long run distribution is applicable here.

Our queueing model is finite and different from the ones that come from a finite population. Unlike ordinary queuing model, the proposed queuing model has a specified number of customers that come to the system in a fixed window time.

The number of trucks is constant, and the arrival time is within a fixed window time, obeying a uniform or beta distribution. This queueing system is called a finite queueing system. Therefore, the waiting time cannot be calculated by the classic methods.

Some papers have studied the finite population queueing systems. Louchard [28] studied the finite population queueing system with non-Markovian properties and a general service time. In order to obtain diffusion approximations, he considered particular short time intervals; in addition, the processes could be locally Markovian. This approximation is appropriate for a large number of population.

Jain et al. [29] introduced the concert queueing problem with the finite number of customers arriving at a queueing system, and the service time starts and finishes at a specified time window. They maintained that the number of customers is random with a finite mean, $E(N)$, and the service times of customers are identical independent distributions.

Honnappa et al. [30] proposed a queueing model with ordered arrivals of a fixed, finite population, which can be called $\Delta(i) / G I / 1$ queue. The arrival times are order statistic, and a single server with independent and identically distributed service times serves the customers. They computed the waiting time of a customer by an approximation method. In addition, they developed fluid and diffusion limits for the performance metrics of the queue.

Some of the papers have studied the optimization of queueing system's trucks. Chen et al. [31] analyzed the terminal gate system with the non-stationary queuing model and proposed an approximation to solve the model. They also applied an optimization model to reduce the truck queueing.

Although some of the real cases and the numbers of population are finite, all of these studies consider a queuing system that operates forever with an infinite population of customers.

Motaghedi-Larijani and Aminnayeri [32] studied the queuing model with one server and a fixed number of customers to optimize the length of time window. Our research is concerned with computing the waiting time of outbound trucks in the crossdock to optimize the number of outbound doors. Studies of finite queuing systems focus on the diffusion approximation method. Unlike the mentioned papers, the joint conditional order statistics are used herein to compute the expected waiting time of customers with the proposed exact method as in [32]. Herein, a finite queueing system with multi-servers is developed and the expected waiting time of customers is computed.

The notations in [32] are extended to present this finite queueing model as $(n, B, L) / D / m$ where $n$ stands for the number of customers, $B$ stands for a beta distribution of arrivals, $l$ stands for the length of arrival time window, $D$ is the constant service time, and $m$ is the number of servers. To the best of our knowledge, this paper is the first research in crossdocks with a finite queueing model, computing the expected waiting time of trucks and optimizing the number of outbound doors for multiple servers. The rest of this paper is organized as follows: In Section 2, the problem of the 
finite queueing model in a crossdock is detailed. The calculation method of the expected waiting time of [32] is developed in Section 3. Experimental results are shown in the next section. Conclusion and discussion appear in the last section.

\section{The problem description}

This study is motivated with a realistic problem related to a supply chain with a crossdock. A distribution center with a fixed number of trucks should deliver products to retailers in the crossdock. These trucks have to arrive within a fixed time window in early morning of every day. However, these trucks arrive at random during the time window $[0, L]$. It is assumed that there is a temporary storage in front of the outbound doors. At first, the products are unloaded through the outbound doors; then, they are stored in the temporary storage. Therefore, the shipping products are ready to be delivered to customers. A fixed number of outbound trucks, $n$, arriving at random time, $x_{j}, j=1, \cdots, n$, with a beta distribution on $[0, l]$ are to be loaded. The proposed crossdock model is shown in Figure 1

The service time of each truck is a constant time $d$. Outbound doors are considered as servers. There are two possibilities for truck $i=1, \cdots, n$ arriving at the facility. Either at least one server is idle or it will wait on the queue to receive service. The arrival times of trucks are independent random variables with a beta distribution on $[0, l]$. Because uniform distribution is a special case of the beta distribution, in order to simplify the calculation, the uniform distribution is used. Let $x_{1}, x_{2}, \cdots, x_{n}$ be $n$ independent random variables with uniform distribution on $[0, l]$ within:

$$
f(x)=\frac{1}{l} \quad 0 \prec x \prec L .
$$

Let $t_{1}, t_{2}, \cdots, t_{n}$ be the order statistics of $X j^{\prime} s, j=$ $1, \cdots, n$. The problem is to minimize costs of waiting times and service facility simultaneously. The decision variable is $m$, as the number of outbound doors. The

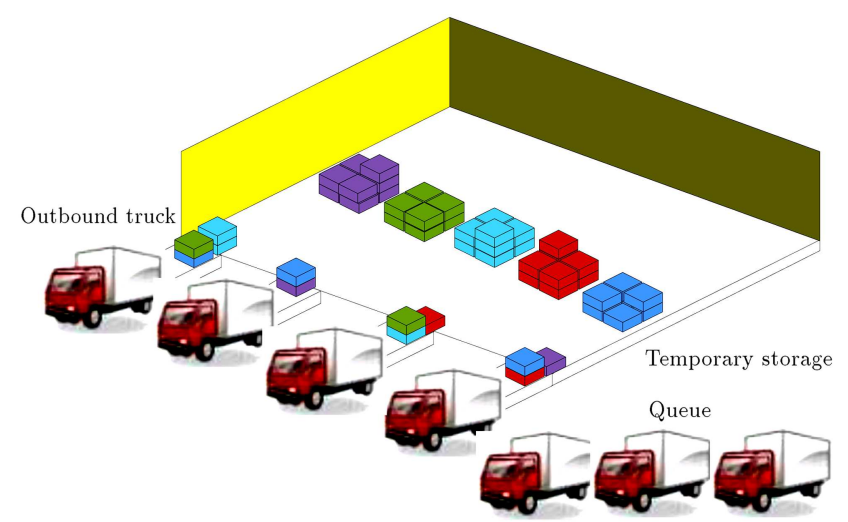

Figure 1. The proposed crossdock model. joint conditional probability of order statistics is used to calculate the expected waiting time.

A fixed number of customers arrive at the system in a fixed time window. These features make the model become non-stationary, and the steady state probabilities cannot be calculated. Development of a queueing model for outbound trucks in the crossdock along with the calculation of the expected waiting times and optimization of the number of outbound trucks as servers will be our contributions.

\section{Characteristics of the proposed model:}

- The service time, $d$, is fixed;

- The total number of customers, $n$, to be served is fixed;

- The arrival time, $X j^{\prime} s, j=1, \cdots, n$, is a random variable with the uniform distribution on $[0, L]$, in which $L$ is fixed;

- The policy of the queue is First-In, First-Out (FIFO);

- The service process continues until all customers receive the service;

- The number of outbound doors, $m$, is the decision variable considered as servers.

The notation of queueing model is defined as follows:

$t_{i} \quad$ The arrival time of the $i$ th customer being the order statistics of $X j^{\prime} s, j=$ $1, \cdots, n$;

$e_{i} \quad$ The leaving time of the $i$ th customer;

$W_{i} \quad$ The random waiting time of the $i$ th customer;

$E\left(W_{i}\right) \quad$ The expected value of waiting time of the $i$ th customer in the queue.

If at least one server is idle at the arrival time, $t_{i}$, of the $i$ th customer, then:

$$
e_{i}=t_{i}+d
$$

Otherwise $e_{i}$ satisfies Eq. (2):

$$
e_{i}=e_{i-m}+d
$$

\section{The calculation method}

The challenge of the proposed model is that the model has no steady state. Therefore, probability distribution of the model, such as the distribution of $W_{i}$, is not in hand. Based on the conditional joint probabilities of order statistics along with the Bayes theorem, the expected waiting time of customers in the queue is calculated. At the arrival time of a customer, two situations may occur: Either at least one server is idle 
or it will wait in the queue to get service. We will assert and prove two propositions and use them to calculate the expected waiting time, $E\left(W_{j}\right)$.

All customers will be served according to FIFO policy. Let $n$ be the number of customers that have to arrive during a time window $[0, L]$. Let $t_{1}, t_{2}, \cdots, t_{n}$ be the order arrival times of customers. It is clear that:

$$
0<t_{1}<t_{2}<\cdots<t_{n-1}<t_{n}<L .
$$

Because $m$ servers are ready at the start of time window, the first $m$ customers should not wait in the queue. Due to the fixed service time, $d$, based on the order of entry, customers are divided into $m$ categories. Let $r$ be $j$ modulo $m, r=0,1, \cdots, m-1 \cdots$. Based on this category, we have $m$ separate problems. Hence, the $j$ th customer waits until the end of $(j-m)$ th customer service. For better understanding, consider a problem with 3 servers and 20 customers; based on the order of entry, the categories of customers are:

$$
\begin{array}{ll}
r=1, & {[1,4,7,10,13,16,19],} \\
r=2, & {[2,5,8,11,14,17,20],} \\
r=0, & {[3,6,9,12,15,18] .}
\end{array}
$$

Each category has the same module for $m$. For example, the 13th customer waits until the end of the 10th customer service time.

Let us consider a $2 \times n$ probability matrix $P_{e}$. The $j$ th component of the first row of $P_{e}$ shows the probability that at least one server in the system is idle at the arrival of the $j$ th customer, $j=1, \cdots n$. The $j$ th component of the second row of $P_{e}$ shows the probability that the system is busy at the arrival of the $j$ th customer, $j=1, \cdots n$. Hence, by calculating the first row, the entries of the second row could be calculated by Eq. (3) as shown in Box I.

It is obvious that for the queuing system with $m$ servers, the event that results in $e_{j}=t_{j}+d$ is equivalent to the event in which $e_{j-m} \leq t_{j}$. Therefore:

$$
P\left(e_{j}=t_{j}+d\right)=P\left(e_{j-m} \leq t_{j}\right) .
$$

Suppose that $A_{j}$ is the event in which there is no customer in the system at the arrival time of the $j$ th customer. Therefore, $A_{j}^{\prime}$ would be the event in which there is at least one customer in the system at the arrival time of the $j$ th customer. In other words, $P\left(A_{j}\right)$ means that:

$$
P\left(A_{j}\right)=P\left(e_{j}=t_{j}+d\right) \text {. }
$$

Proposition 1: If the system has $m$ servers, then the $j$ th component of the first row of matrix $P_{e}$ is calculated by:

$$
\begin{aligned}
& P_{e}(1, j)=1 \quad j \leq m, \\
& P_{e}(1, j)=P\left(e_{j}=t_{j}+d\right) \\
& =P_{e}(1, j-m) P\left(t_{j-m}+d \leq t_{j}\right) \\
& \quad+\sum_{i=1}^{\frac{j-z}{m}-1}\left(P_{e}(1, m(i-1)+z)\right. \\
& \quad \times P\left(t_{m(i-1)+z}+\left(\frac{j-m(i-1)-z}{m}\right) d \leq t_{j}\right) \\
& \left.\quad \times\left(\prod_{h=i+1}^{\frac{j-z}{m}} P_{e}(2, m(h-1)+z)\right)\right) \quad j>m,
\end{aligned}
$$

where $r=(j(\bmod m))$, and $z=m$ if $r=0$; otherwise, $z=r$.

Proof: The proposition is proved based on the mentioned categorization. It is obvious that there is no waiting time for the $j$ th customer, $1 \leq j \leq m$. For the $j$ th customer, $m+1 \leq j \leq 2 m$, the expected waiting time of the $j$ th customer can be computed using the following conditional probability formula:

$$
\begin{aligned}
P\left(A_{j}\right)= & P\left(A_{j} \cap A_{j-m}\right)+P\left(A_{j} \cap A_{j-m}^{\prime}\right), \\
P\left(A_{j}\right)= & P\left(A_{j-m}\right) P\left(A_{j} \mid A_{j-m}\right) \\
& +P\left(A_{j-m}^{\prime}\right) P\left(A_{j} \mid A_{j-m}^{\prime}\right) .
\end{aligned}
$$

$$
\begin{aligned}
& P\left(e_{j}=e_{j-m}+d\right)=1-P\left(e_{j}=t_{j}+d\right),
\end{aligned}
$$

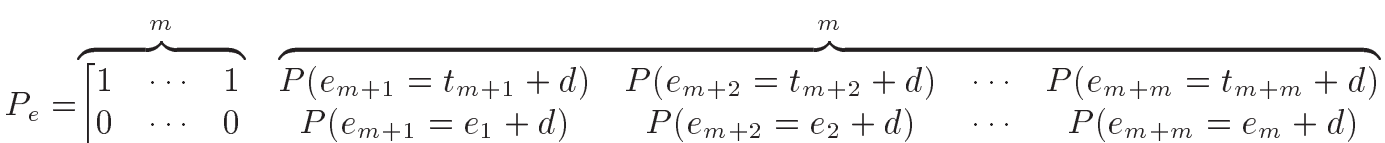

$$
\begin{aligned}
& \left.\begin{array}{cc}
\cdots & P\left(e_{n}=t_{n}+d\right) \\
\cdots & P\left(e_{n}=e_{n-m}+d\right)
\end{array}\right] .
\end{aligned}
$$


We know that:

$$
P\left(A_{j-m}^{\prime}\right)=0, \quad j \leq m .
$$

Therefore, the right hand side of Eq. (9) is:

$$
\begin{aligned}
P\left(e_{j}=\right. & \left.t_{j}+d\right)=P\left(e_{j-m}=t_{j-m}+d\right) \\
& P\left(e_{j}=t_{j}+d \mid e_{j-m}=t_{j-m}+d\right), \\
P\left(e_{j}=\right. & \left.t_{j}+d\right)=P\left(e_{j-m}=t_{j-m}+d\right) \\
& P\left(e_{j-m} \leq t_{j} \mid e_{j-m}=t_{j-m}+d\right) \\
= & P\left(e_{j-m}=t_{j-m}+d\right) P\left(t_{j-m}+d \leq t_{j}\right) \\
= & P_{e}(1, j-m) P\left(t_{j-m}+d \leq t_{j}\right) .
\end{aligned}
$$

Therefore, for the $j$ th component of Eq. (6), the proof is complete. In order to compute the $j$ th component $j>2 m$, the following conditional probability is used to extract a recursive relationship:

$$
\begin{aligned}
P\left(A_{j}\right)= & P\left(A_{j-m}\right) P\left(A_{j} \mid A_{j-m}\right) \\
& +P\left(A_{j-m}^{\prime}\right) P\left(A_{j} \mid A_{j-m}^{\prime}\right), \\
P\left(e_{j}=\right. & \left.t_{j}+d\right)=P\left(e_{j-m}=t_{j-m}+d\right) \\
& P\left(e_{j}=t_{j}+d \mid e_{j-m}=t_{j-m}+d\right) \\
& +P\left(e_{j-m}=e_{j-2 m}+d\right) \\
& P\left(e_{j}=t_{j}+d \mid e_{j-m}=e_{j-2 m}+d\right), \\
P\left(e_{j}=\right. & \left.t_{j}+d\right)=P_{e}(1, j-m) \\
& P\left(e_{j-m} \leq t_{j} \mid e_{j-m}=t_{j-m}+d\right) \\
& +P_{e}(2, j-m) \\
& P\left(e_{j-m} \leq t_{j} \mid e_{j-m}=e_{j-2 m}+d\right) \\
= & P(1, j-m) P\left(t_{j-m}+d \leq t_{j}\right) \\
& +P_{e}(2, j-m) P\left(e_{j-2 m}+d \leq t_{j}\right) .
\end{aligned}
$$

The conditional probability is repeated to compute $P\left(e_{j-2 m}+d \leq t_{j}\right)$ :

$$
\begin{aligned}
& P\left(e_{j-2 m}+d \leq t_{j}\right) \\
& \quad=P\left(e_{j-2 m}+d \leq t_{j}, e_{j-2 m}=e_{j-3 m}+d\right) \\
& \quad+P\left(e_{j-2 m}+d \leq t_{j}, e_{j-2 m}=t_{j-2 m}+d\right),
\end{aligned}
$$

$$
\begin{gathered}
P\left(e_{j-2 m}+d \leq t_{j}\right)=P\left(e_{j-2 m}=e_{j-3 m}+d\right) \\
P\left(e_{j-2 m}+d \leq t_{j} \mid e_{j-2 m}=e_{j-3 m}+d\right) \\
\quad+P\left(e_{j-2 m}=t_{j-2 m}+d\right) \\
P\left(e_{j-2 m}+d \leq t_{j} \mid e_{j-2 m}=t_{j-2 m}+d\right) \\
=P\left(e_{j-2 m}=e_{j-3 m}+d\right) P\left(e_{j-3 m}+2 d \leq t_{j}\right) \\
\quad+P\left(e_{j-2 m}=t_{j-2 m}+d\right) P\left(t_{j-2 m}+2 d \leq t_{j}\right) .
\end{gathered}
$$

The right hand side of Eq. (17) is inserted into Eq. (12) as follows:

$$
\begin{aligned}
& P\left(e_{j}=t_{j}+d\right)=P_{e}(1, j-m) P\left(t_{j-m}+d \leq t_{j}\right) \\
& \quad+P_{e}(2, j-m)\left(P\left(e_{j-2 m}=e_{j-3 m}+d\right)\right. \\
& P\left(e_{j-3 m}+2 d \leq t_{j}\right)+P\left(e_{j-2 m}=t_{j-2 m}+d\right) \\
& \left.\quad P\left(t_{j-2 m}+2 d \leq t_{j}\right)\right) \\
& P\left(e_{j}=t_{j}+d\right)=P_{e}(1, j-m) P\left(t_{j-m}+d \leq t_{j}\right) \\
& \quad+P_{e}(2, j-m)\left(P_{e}(2, j-2 m) P\left(e_{j-3 m}+2 d \leq t_{j}\right)\right. \\
& \left.\quad+P_{e}(1, j-2 m) P\left(t_{j-2 m}+2 d \leq t_{j}\right)\right) .
\end{aligned}
$$

For the $j$ th customer, $1 \leq j-3 m \leq m$, the proposition is proved. For the $j$ th customer for which $j>4 m$, the mentioned conditional probability is repeated in order to compute $P\left(e_{j-3 m}+2 d \leq t_{j}\right)$. These computations are repeated as far as $j-i m \leq m$. The proposition is proved.

To calculate $P\left(t_{i}+(j-i) d \leq t_{j}\right)$, a joint order statistic distribution of arrival time of customers $i$ and $j$ is used, i.e.:

$$
\begin{aligned}
f\left(t_{i}, t_{j}\right)= & \frac{n !}{(i-1) !(j-i-1) !(n-j) !}\left[F\left(t_{i}\right)\right]^{i-1} \\
& {\left[F\left(t_{j}\right)-F\left(t_{i}\right)\right]^{j-i-1}\left[1-F\left(t_{j}\right)\right]^{n-j} } \\
& f\left(t_{i}\right) f\left(t_{j}\right) \quad j>i, \\
f\left(t_{i}, t_{j}\right)= & \frac{n !}{(i-1) !(j-i-1) !(n-j) !}\left[\frac{t_{i}}{L}\right]^{i-1} \\
j>i, & {\left[\frac{t_{j}}{L}-\frac{t_{i}}{L}\right]^{j-i-1}\left[1-\frac{t_{j}}{L}\right]^{n-j}\left(\frac{1}{L}\right)^{2} } \\
j &
\end{aligned}
$$

where $f(t)=\frac{1}{L}$ and $F(t)=\frac{t}{L}$. Therefore:

$$
P\left(t_{i}+(j-i) d \leq t_{j}\right)=\iint_{t_{i}+(j-i) d \leq t_{j}} f\left(t_{i}, t_{j}\right) d t_{i} d t_{j}
$$


This matrix will be used to calculate the expected waiting time in the queue. If the servers are busy at the arrival time of the $j$ th customer, the waiting time of the $j$ th customer is $w_{j}=e_{j}-\left(t_{j}+d\right)$. In order to calculate the expected waiting time of the $j$ th customer, there are $k$ possibilities in which $k$ is:

$$
k=\frac{j-z}{m}+1 \text {. }
$$

The possibility one is that $t_{j}<e_{z}$ and the possibility $i, 1<i \leq k$ is $e_{m(i-2)+z}<t_{j} \leq e_{m(i-1)+z}$. For the $j$ th customer, the possibility one means that $e_{j}=t_{z}+k d$; hence, the expected waiting time of this possibility is:

$$
E\left(w_{j}\right)=E\left(t_{z}+k d-t_{j}-d\right) .
$$

Likewise, for possibility $i$, the expected waiting time of the $j$ th customer is:

$$
\begin{aligned}
& w_{j}=t_{m(i-1)+z}+\left(\frac{j-(m(i-1)+z)}{m}\right) d-t_{j}, \\
& E\left(w_{j}\right)=E\left(t_{m(i-1)+z}+\left(\frac{j-(m(i-1)+z)}{m}\right) d-t_{j}\right) .
\end{aligned}
$$

Therefore, the waiting time of possibility $k$ is zero and $E\left(w_{j}\right)=0$. To calculate the probability of each possibility, Proposition 2 is used.

Proposition 2: Let $M_{i j}$ be the event in which the exiting time of the $j$ th customer is:

$$
e_{j}=t_{m(i-1)+z}+\left(\frac{j-(m(i-1)+z)}{m}\right) d+d,
$$

or:

$$
w_{j}=t_{m(i-1)+z}+\left(\frac{j-(m(i-1)+z)}{m}\right) d-t_{j},
$$

and then:

$$
\begin{aligned}
& P\left(M_{i j}\right)=P_{e}(1, m(i-1)+z) \\
& \quad \times\left(\prod_{h=i+1}^{k} p\left(t_{m(h-1)+z} \leq t_{m(i-1)+z}+(h-i) d\right)\right)
\end{aligned}
$$

$\forall i<k$.

Proof: Based on our definition, we have:

$$
\begin{aligned}
M_{i j}= & A_{m(i-1)+z} \cap A_{m(i)+z}^{\prime} \cap \cdots \cap A_{m(k-2)+z}^{\prime} \\
& \cap A_{m(k-1)+z}^{\prime},
\end{aligned}
$$

and:

$$
\begin{aligned}
P\left(M_{i j}\right)= & P\left(A_{m(i-1)+z} \cap A_{m(i)+z}^{\prime} \cap \cdots\right. \\
& \left.\cap A_{m(k-2)+z}^{\prime} \cap A_{m(k-1)+z}^{\prime}\right),
\end{aligned}
$$

where $j$ is:

$$
j=m(k-1)+z .
$$

In order to compute $P\left(M_{i j}\right)$, the Bayes' theorem should be applied. By using this theorem, we have:

$$
\begin{aligned}
P\left(M_{i j}\right)= & P\left(A_{m(k-1)+z}^{\prime} \mid A_{m(i-1)+z} \cap A_{m(i)+z}^{\prime}\right. \\
& \left.\cap \cdots \cap A_{m(k-2)+z}^{\prime}\right) \\
& \times P\left(A_{m(k-2)+z}^{\prime} \mid A_{m(i-1)+z} \cap A_{m(i)+z}^{\prime}\right. \\
& \left.\cap \cdots \cap A_{m(k-3)+z}^{\prime}\right) \\
& \times \cdots \times P\left(A_{m(i)+z}^{\prime} \mid A_{m(i-1)+z}\right) \\
& \times P\left(A_{m(i-1)+z}\right) \quad 1 \leq i<k .
\end{aligned}
$$

In other words, we can write:

$$
\begin{aligned}
P & \left(A_{m(k-1)+z}^{\prime} \mid A_{m(i-1)+z} \cap A_{m(i)+z}^{\prime} \cap \cdots \cap A_{m(k-2)+z}^{\prime}\right) \\
& =P\left(e_{m(k-1)+z}=e_{m(k-2)+z}+d \mid e_{m(i-1)+z}\right. \\
& =t_{m(i-1)+z}+d, e_{m(i)+z} \\
& \left.=e_{m(i-1)+z}+d, \cdots, e_{m(k-2)+z}=e_{m(k-3)+z}+d\right) .
\end{aligned}
$$

By inserting the conditional term, Eq. (30) is transformed into:

$$
\begin{aligned}
P & \left(A_{m(k-1)+z}^{\prime} \mid A_{m(i-1)+z} \cap A_{m(i)+z}^{\prime} \cap \cdots \cap A_{m(k-2)+z}^{\prime}\right) \\
& =P\left(e_{m(k-1)+z}=t_{m(i-1)+z}+(k-i) d+d\right) . \quad(31)
\end{aligned}
$$

For each number $i<x<k$, the conditional terms of Eq. (29) is:

$$
\begin{aligned}
& P\left(A_{m(x-1)+z}^{\prime} \mid A_{m(i-1)+z} \cap A_{m(i)+z}^{\prime} \cap \cdots \cap A_{m(x-2)+z}^{\prime}\right) \\
& \quad=P\left(e_{m(x-1)+z}=t_{m(i-1)+z}+(x-i) d+d\right) .
\end{aligned}
$$

The right hand side of Eq. (31) can be written as follows:

$$
\begin{aligned}
& P\left(e_{m(x-1)+z}=t_{m(i-1)+z}+(x-i) d+d\right) \\
& \quad=P\left(t_{m(x-1)+z} \leq t_{m(i-1)+z}+(x-i) d\right) .
\end{aligned}
$$

The probability of each event $M_{i j}$ for the multiple servers is shown in Table 1. 
Table 1. Computing the expected value of waiting time of the $j$ th customer in queue for multi servers $(j=m k+z)$.

\begin{tabular}{|c|c|c|c|}
\hline $\begin{array}{l}\text { Number } \\
\text { of events }\end{array}$ & Events & The probability of event & $\begin{array}{l}\text { Expected value } \\
\text { of waiting } \\
\text { time in queue }\end{array}$ \\
\hline 1 & $t_{z}+\frac{j-z}{m} d$ & $P\left(M_{1 j}\right)=P_{e}(1, z) \times\left(\prod_{h=2}^{k} P\left(t_{m(h-1)+z} \leq t_{z}+(h-1) d\right)\right)$ & $E\left(t_{z}+\frac{j-z}{m} d-t_{j}\right)$ \\
\hline 2 & $t_{m+z}+\frac{j-(m+z)}{m} d$ & $\begin{aligned} P\left(M_{2 j}\right)= & P_{e}(1, m+z) \\
& \times\left(\prod_{h=3}^{k} P\left(t_{m(h-1)+z} \leq t_{m+z}+(h-2) d\right)\right)\end{aligned}$ & $E\left(t_{m+z}+\frac{j-(m+z)}{m} d-t_{j}\right)$ \\
\hline$\vdots$ & $\vdots$ & $\vdots$ & $\vdots$ \\
\hline$k-1$ & $t_{m(k-2)+z}+d$ & $\begin{aligned} P\left(M_{k-1, j}\right)= & P_{e}(1, m(k-2)+z) \\
& \times P\left(t_{m(k-1)+z} \leq t_{m(k-2)+z}+d\right)\end{aligned}$ & $E\left(t_{m(k-2)+z}+d-t_{j}\right)$ \\
\hline$K$ & $t_{m(k-1)+z}$ & $P\left(M_{j j}\right)=1-\sum_{i=1}^{k-1} P\left(M_{i j}\right)$ & 0 \\
\hline
\end{tabular}

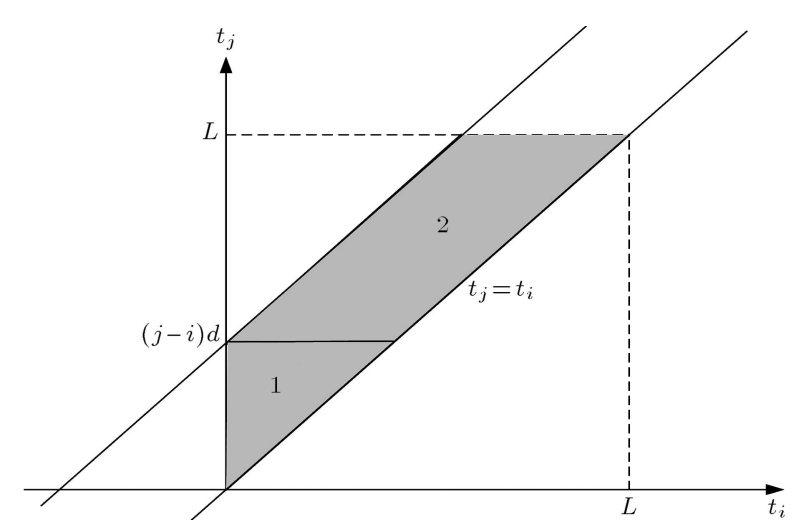

Figure 2. Integration integral if $(j-i) d<L$.

Now, the expected waiting time of the customer $j^{\text {th }}$ is calculated for multi-server queueing model according to probability $P\left(M_{i j}\right)$ from Table 1 . Now, waiting time of the customer $j^{h}$ is as follows:

$$
\begin{aligned}
E\left(w_{j}\right)= & \sum_{i=1}^{k-1}\left(P M_{(m(i-1)+z) j}\right) E\left(t_{m(i-1)+z}\right. \\
& \left.\left.+(k-i) d-t_{m(k-1)+z}\right)\right), \\
j= & m(k-1)+z .
\end{aligned}
$$

The right hand side of Eq. (34) is calculated by the joint density function of order statistics. There are two possibilities, (a) and (b), to compute the joint density functions of order statistics $t_{i}$ and $t_{j}$ :
(a) $(j-i) d \leq l$;
(b) $(j-i) d>L$.

The intervals of integration used to calculate each of possibilities (a) and (b) are shown in Figures 2 and 3, respectively.

In order to compute the expected value of $E\left(t_{i}+\right.$ $\left.(j-i) d-t_{j}\right)$, the integration intervals should be taken into account. Two conditions to compute this integral are as follows:

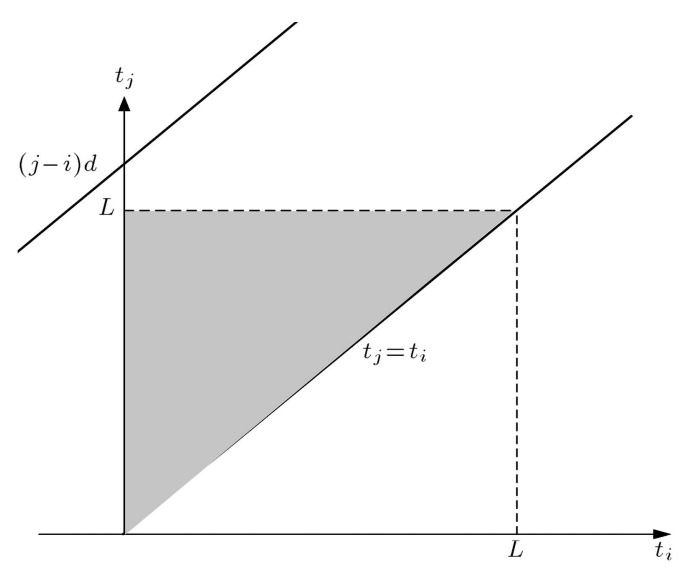

Figure 3. Integration integral if $(j-i) d>L$.

$$
\begin{aligned}
& E\left(t_{i}+(j-i) d-t_{j}\right) \\
& =\int_{0}^{(j-i) d} \int_{0}^{t_{j}}\left(t_{i}+(j-i) d-t_{j}\right) f\left(t_{i}, t_{j}\right) d t_{i} d t_{j} \\
& \quad+\int_{(j-i) d t_{j}-(j-i) d}^{L}\left(t_{i}+(j-i) d-t_{j}\right) f\left(t_{i}, t_{j}\right) d t_{i} d t_{j}, \\
& \text { if } \quad(j-i) d \leq L, \\
& E\left(t_{i}+(j-i) d-t_{j}\right) \\
& =\int_{0}^{L} \int_{0}^{t_{j}}\left(t_{i}+(j-i) d-t_{j}\right) f\left(t_{i}, t_{j}\right) d t_{i} d t_{j}, \\
& \text { if } \quad(j-i) d>L .
\end{aligned}
$$

\section{Numerical results}

Some test problems are used to show the application of 
the model in reality. Each problem is characterized by three features: the number of customers, the number of servers, and length of the arrival time window for customers. The features of the test problems are:

- Number of customers: 10, 15, 20, 25, 30, 35, 40, 50, 60 ;

- Number of servers: $1,2,3,4,5,6,7,8,9$;

- Length of time window: 5, 6, 8, 10 .
We consider 0.5 unit of time on the fixed service time for all of the test problems. The expected waiting time of customers for different examples is calculated and shown in Tables 2 to 5 .

For a better understanding, steps required to solve the problem of $(n, U, L) / D / 3$ with 20 customers and 5 units of time window will be shown.

At first, $P_{e}$ matrix should be calculated by Proposition 1:

Table 2. The expected value of average waiting time of customers with 0.5 hours of service time and length of time windows of 5 hours.

\begin{tabular}{cccccccccc}
\hline \multirow{2}{*}{$\begin{array}{c}\text { No. of } \\
\text { customer }\end{array}$} & \multicolumn{7}{c}{ Number of servers } \\
\cline { 2 - 10 } & $\mathbf{1}$ & $\mathbf{2}$ & $\mathbf{3}$ & $\mathbf{4}$ & $\mathbf{5}$ & $\mathbf{6}$ & $\mathbf{7}$ & $\mathbf{8}$ & $\mathbf{9}$ \\
\hline 10 & 0.1532 & 0.0092 & 0.0004 & - & - & - & - & - & - \\
15 & $\mathbf{1 . 0 3 2 3}$ & 0.0335 & 0.0036 & 0.0003 & - & - & - & - & - \\
20 & $\mathbf{2 . 3 7 4 8}$ & 0.0982 & 0.0125 & 0.0016 & 0.0001 & - & - & - & - \\
25 & $\mathbf{3 . 6 4 3 6}$ & $\mathbf{0 . 4 2 5 9}$ & 0.0316 & 0.0056 & 0.0008 & - & - & - & - \\
30 & $\mathbf{4 . 8 9}$ & $\mathbf{1 . 0 9}$ & 0.0763 & 0.0138 & 0.0027 & - & - & - & - \\
35 & $\mathbf{6 . 1 2 6}$ & $\mathbf{1 . 7 5 6 8}$ & $\mathbf{0 . 2 5 5 3}$ & 0.0297 & 0.0067 & 0.0013 & - & - & - \\
40 & $\mathbf{7 . 3 6 5}$ & $\mathbf{2 . 3 9 1}$ & $\mathbf{0 . 6 6 7 2}$ & 0.0641 & 0.0143 & 0.0035 & 0.0007 & - & - \\
50 & - & - & - & $\mathbf{0 . 4 6 3 3}$ & 0.0561 & 0.0145 & 0.0041 & 0.0010 & - \\
60 & - & - & - & - & - & 0.0504 & 0.0145 & 0.0045 & 0.0013 \\
\hline
\end{tabular}

Table 3. The expected value of average waiting time of customers with 0.5 hours of service time and length of time windows of 6 hours.

\begin{tabular}{|c|c|c|c|c|c|c|c|c|}
\hline \multirow{2}{*}{$\begin{array}{c}\text { No. of } \\
\text { customer }\end{array}$} & \multicolumn{8}{|c|}{ Number of servers } \\
\hline & 1 & 2 & 3 & 4 & 5 & 6 & 7 & 8 \\
\hline 10 & 0.0931 & 0.0053 & 0.0002 & - & - & - & - & - \\
\hline 15 & - & 0.0194 & 0.0016 & - & - & - & - & - \\
\hline 20 & - & 0.0490 & 0.0061 & 0.0006 & - & - & - & - \\
\hline 25 & - & - & 0.0153 & 0.0022 & - & - & - & - \\
\hline 30 & - & 一 & 0.0325 & 0.0058 & 0.0008 & - & - & - \\
\hline 35 & - & - & 0.0670 & 0.0124 & 0.0023 & - & - & - \\
\hline 40 & - & - & - & 0.0239 & 0.0053 & 0.0010 & - & - \\
\hline 50 & 一 & - & - & - & 0.0186 & 0.0048 & 0.0011 & - \\
\hline 60 & - & - & - & - & 0.0578 & 0.0150 & 0.0043 & 0.0011 \\
\hline
\end{tabular}

Table 4. The expected value of average waiting time of customers with 0.5 hours of service time and length of time windows of 8 hours.

\begin{tabular}{cccccccc}
\hline \multirow{2}{*}{$\begin{array}{c}\text { No. of } \\
\text { customer }\end{array}$} & $\mathbf{1}$ & $\mathbf{2}$ & $\mathbf{3}$ & $\mathbf{4}$ & $\mathbf{5}$ & $\mathbf{6}$ & $\mathbf{7}$ \\
\cline { 2 - 8 } & 0.0509 & 0.0021 & - & - & - & - & - \\
10 & 0.1295 & 0.0082 & 0.0004 & - & - & - & - \\
20 & - & 0.0201 & 0.0018 & - & - & - & - \\
25 & - & 0.0406 & 0.0049 & 0.0004 & - & - & - \\
30 & - & 0.0780 & 0.0104 & 0.0013 & - & - & - \\
35 & - & - & 0.0194 & 0.0031 & 0.0004 & - & - \\
40 & - & - & 0.0337 & 0.0061 & 0.0009 & - & - \\
50 & - & - & 0.1051 & 0.0181 & 0.0038 & 0.0007 & - \\
60 & - & - & - & 0.0461 & 0.0108 & 0.0025 & 0.0005 \\
\hline
\end{tabular}


Table 5. The expected value of average waiting time of customers with 0.5 hours of service time and length of time windows of 10 hours.

\begin{tabular}{ccccccc}
\hline \multirow{2}{*}{$\begin{array}{c}\text { No. of } \\
\text { customer }\end{array}$} & \multicolumn{7}{c}{ Number of servers } \\
\cline { 2 - 7 } & $\mathbf{1}$ & $\mathbf{2}$ & $\mathbf{3}$ & $\mathbf{4}$ & $\mathbf{5}$ & $\mathbf{6}$ \\
\hline 10 & 0.0336 & 0.0009 & - & - & - & - \\
15 & 0.0756 & 0.0042 & 0.0001 & - & - & - \\
20 & 0.1594 & 0.0104 & 0.0006 & - & - & - \\
25 & - & 0.0206 & 0.0019 & 0.0001 & - & - \\
30 & - & 0.0363 & 0.0043 & 0.0004 & - & - \\
35 & - & 0.0611 & 0.0081 & 0.0009 & - & - \\
40 & - & 0.1048 & 0.0139 & 0.0020 & 0.0002 & - \\
50 & - & - & 0.0344 & 0.0063 & 0.0010 & - \\
60 & - & - & 0.0825 & 0.0152 & 0.0031 & 0.0005 \\
\hline
\end{tabular}

Table 6. The expected waiting time of customers with 0.5 hours of service time for 20 customers, 3 servers, and length of time windows of 5 hours.

\begin{tabular}{ccccccccccc}
\hline $\boldsymbol{j}$ & 1 & 2 & 3 & 4 & 5 & 6 & 7 & 8 & 9 & 10 \\
$\boldsymbol{W}_{\boldsymbol{j}}$ & 0 & 0 & 0 & 0.017 & 0.017 & 0.017 & 0.014 & 0.014 & 0.014 & 0.014 \\
$\boldsymbol{j}$ & 11 & 12 & 13 & 14 & 15 & 16 & 17 & 18 & 19 & 20 \\
$\boldsymbol{W}_{\boldsymbol{j}}$ & 0.014 & 0.014 & 0.014 & 0.014 & 0.014 & 0.014 & 0.014 & 0.014 & 0.014 & 0.014 \\
\hline
\end{tabular}

$$
\begin{aligned}
P_{e}= & {\left[\begin{array}{llllll}
1 & 1 & 1 & 0.6769 & 0.6769 & 0.6769 \\
0 & 0 & 0 & 0.3231 & 0.3231 & 0.3231 \\
& 0.718 & 0.718 & 0.718 & 0.7203 \\
& 0.282 & 0.282 & 0.282 & 0.2797
\end{array}\right.}
\end{aligned}
$$$$
\begin{array}{llll}
0.7203 & 0.7203 & 0.7205 & 0.7205
\end{array}
$$$$
\begin{array}{llll}
0.2797 & 0.2797 & 0.2795 & 0.2795
\end{array}
$$$$
\begin{array}{llll}
0.7205 & 0.7205 & 0.7205 & 0.7205
\end{array}
$$$$
\begin{array}{llll}
0.2795 & 0.2795 & 0.2795 & 0.2795
\end{array}
$$

$$
\left.\begin{array}{ll}
0.7204 & 0.7204 \\
0.2796 & 0.2796
\end{array}\right]
$$

The first row of this matrix shows the probability that, at least, one server in the system is idle at the arrival of the $j$ th customer, $j=1, \cdots 20$. For example, the probability that the 7 th customer has no waiting time is 0.718. By using this matrix and Proposition 2, the expected waiting time of each customer is calculated and shown in Table 6 .

Figures 4 to 6 show the expected waiting time of each customer based on its arrival order for some examples. The effect of number of servers on the expected waiting time can be seen easily.

In order to analyze sensitivity of the model to the number of customers, the expected waiting time of customer for 3 servers and 8-unit length of time window is calculated for various number of customers. These

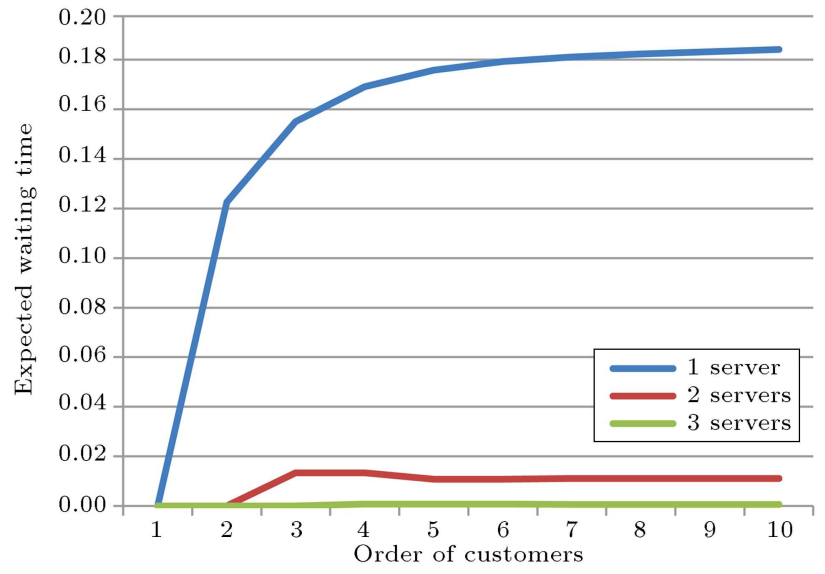

Figure 4. The expected waiting time of each customer based on its arrival order for 10 customers and 5-unit length of time window problem.

sensitivity analyses are shown in Figure 7 . Figure 7 has the exponential curve.

\subsection{Beta distribution arrivals}

In order to compare the expected waiting times of customers based on arrival distribution, a beta distribution is considered for arrivals. Beta distribution is one of the distributions applicable to the proposed model. The probability density function of the beta distribution for $0 \leq t \leq L$ is:

$$
f(t ; \alpha, \beta)=\frac{\Gamma(\alpha+\beta)}{\Gamma(\alpha) \Gamma(\beta)} \frac{1}{L^{\alpha+\beta-1}} t^{\alpha-1}(L-t)^{\beta-1} .
$$




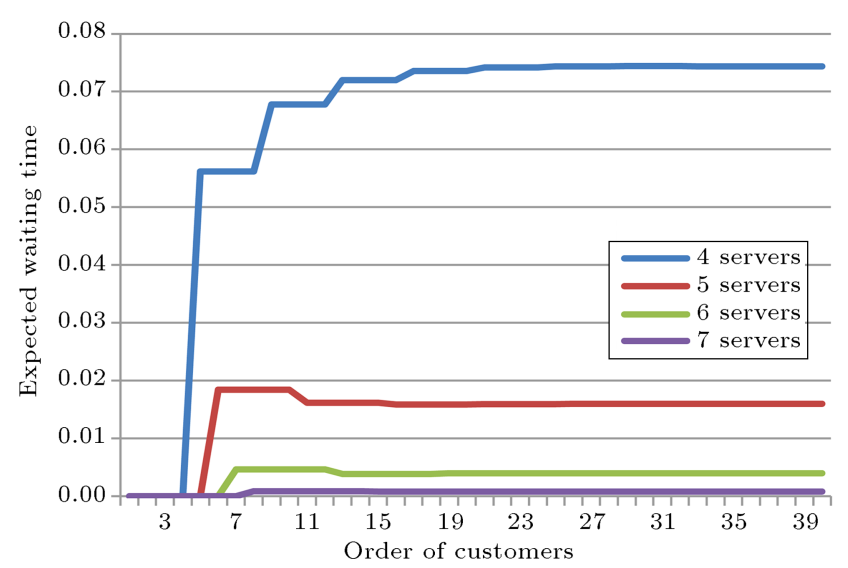

Figure 5. The expected waiting time of each customer based on its arrival order for 40 customers and 5-unit length of time window problem.

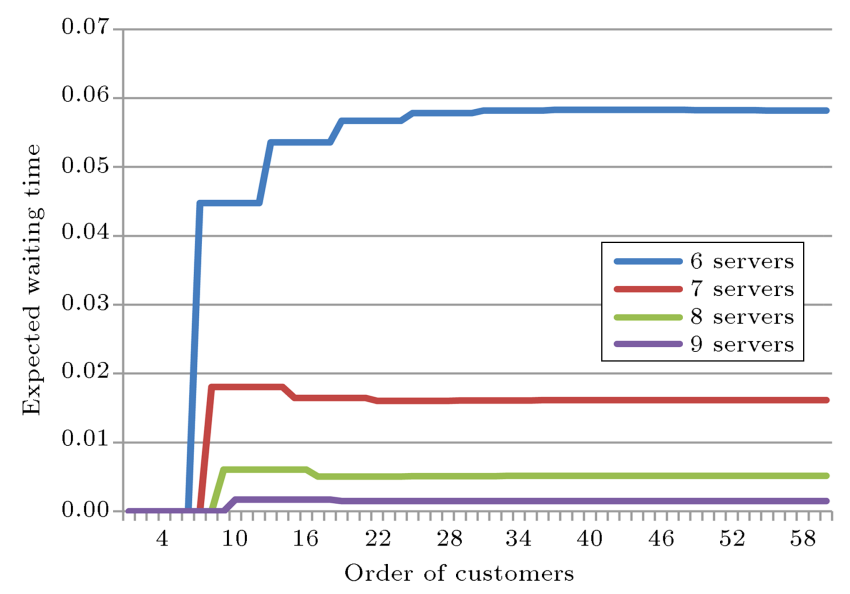

Figure 6. The expected waiting time of each customer based on its arrival order for 60 customers and 5-unit length of time window problem.

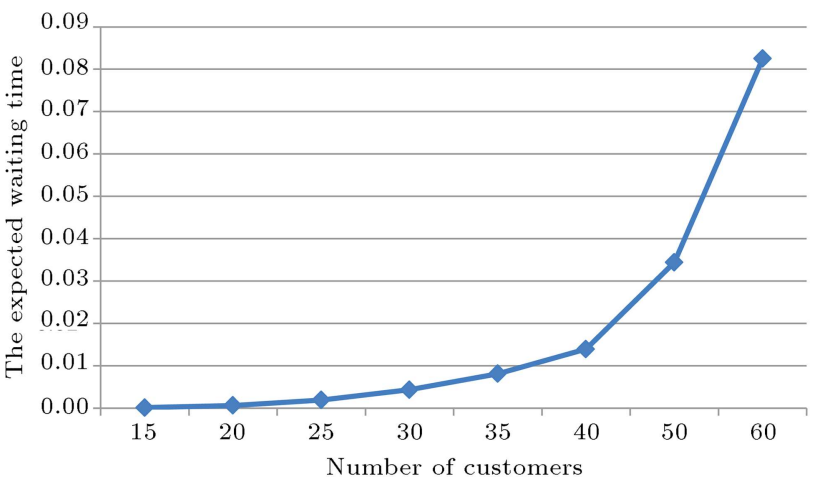

Figure 7. The customer sensitivity analyses of expected waiting time for 3 servers and 8-unit length of time window problem.

In this problem, a limited time window for arrivals is encouraged. If arrivals follow a normal distribution, a truncated normal distribution should be used. Due to simplicity, a beta distribution with parameters $\alpha=2$ and $\beta=2$ can be used instead of the truncated normal.

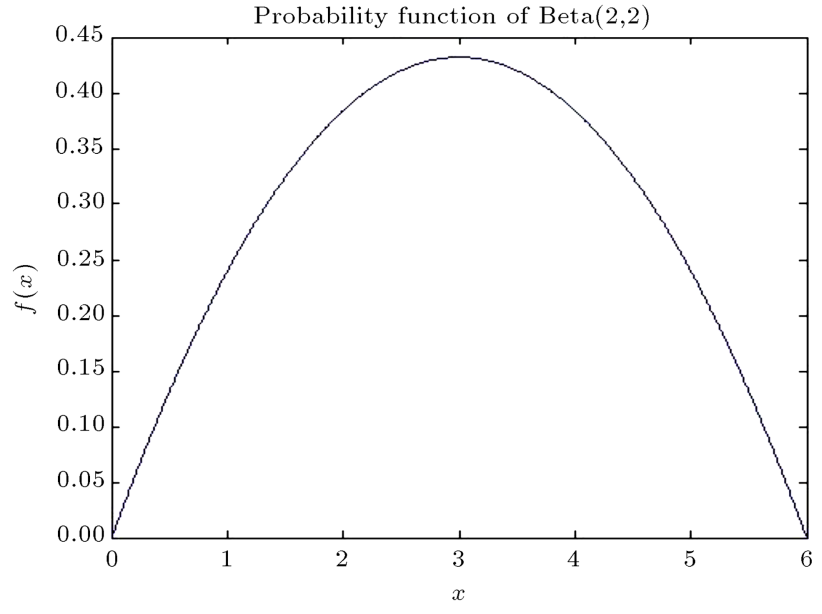

Figure 8. The Probability function of $\operatorname{Beta}(2,2)$.

The probability density function of this distribution is:

$$
f(t ; 2,2)=\frac{6}{L^{3}} t(L-t)
$$

The beta distribution with parameter $\alpha=2, \beta=2$, and $L=6$ is shown in Figure 8 .

The formula for the cumulative distribution function of this distribution is defined as follows:

$$
F(t)=\frac{t^{2}(3 L-2 t)}{L^{3}}, \quad 0 \leq t \leq L, \quad \alpha, \beta=2 .
$$

Based on beta distribution, the joint order statistic distributions of arrival times of the $i^{\text {th }}$ and $j^{\text {th }}$ customers are:

$$
\begin{aligned}
& f\left(t_{i}, t_{j}\right)=\frac{n !}{(i-1) !(j-i-1) !(n-j) !} {\left[\frac{t_{i}^{2}\left(3 L-2 t_{i}\right)}{L^{3}}\right]^{i-1} \frac{6}{L^{3}} t_{i}\left(L-t_{i}\right) } \\
& {\left[\frac{t_{j}^{2}\left(3 L-2 t_{j}\right)}{L^{3}}-\frac{t_{i}^{2}\left(3 L-2 t_{i}\right)}{L^{3}}\right]^{j-i-1} \frac{6}{L^{3}} t_{j}\left(L-t_{j}\right) } \\
& {\left[1-\frac{t_{j}^{2}\left(3 L-2 t_{j}\right)}{L^{3}}\right]^{n-j} \quad j>i, } \\
& f\left(t_{i}, t_{j}\right)=\frac{n !}{(i-1) !(j-i-1) !(n-j) ! L^{3 n}} 36 \\
& {\left[t_{i}^{2}\left(3 L-2 t_{i}\right)\right]^{i-1} t_{i}\left(L-t_{i}\right) } \\
& {\left[t_{j}^{2}\left(3 L-2 t_{j}\right)-t_{i}^{2}\left(3 L-2 t_{i}\right)\right]^{j-i-1} t_{j}\left(L-t_{j}\right) } \\
& {\left[L^{3}-t_{j}^{2}\left(3 L-2 t_{j}\right)\right]^{n-j} \quad j>i . }
\end{aligned}
$$

The proposed method is used to calculate the expected waiting time of customers based on beta distribution 
for arrival times. Two problems with 2 servers, 6 lengths of time window, and 15 and 20 customers are solved.

Based on Figures 9 and 10, the expected waiting time of customers in the uniform case will not exceed 0.026 and 0.056 units of time for 15 and 20 customers' problems, respectively. For both problems in the uniform case, the expected waiting time will tend towards constant values 0.022 and 0.054 for 15 and 20 customers' problems, respectively, until time window is up. However, in the beta case, the expected waiting times reach 0.071 and 0.279 units of time for 15 and 20 customers' problems, respectively. This is obvious because the service time is fixed and uniform arrival is managed better. This dictates to the management of the facility that makes the service by appointment.

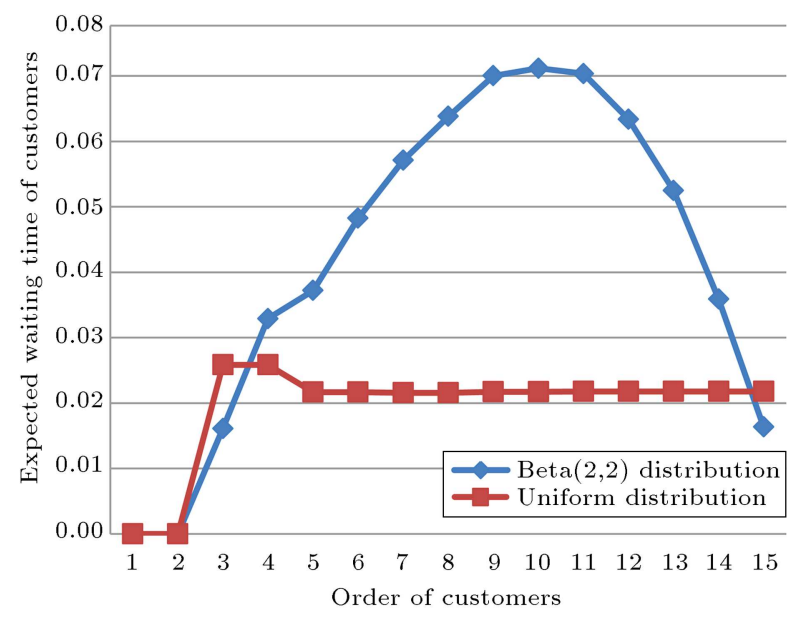

Figure 9. The comparison between uniform and beta arrival distributions for the expected waiting time of each customer based on its arrival order for 15 customers and 6-unit length time and 2 servers' problem.

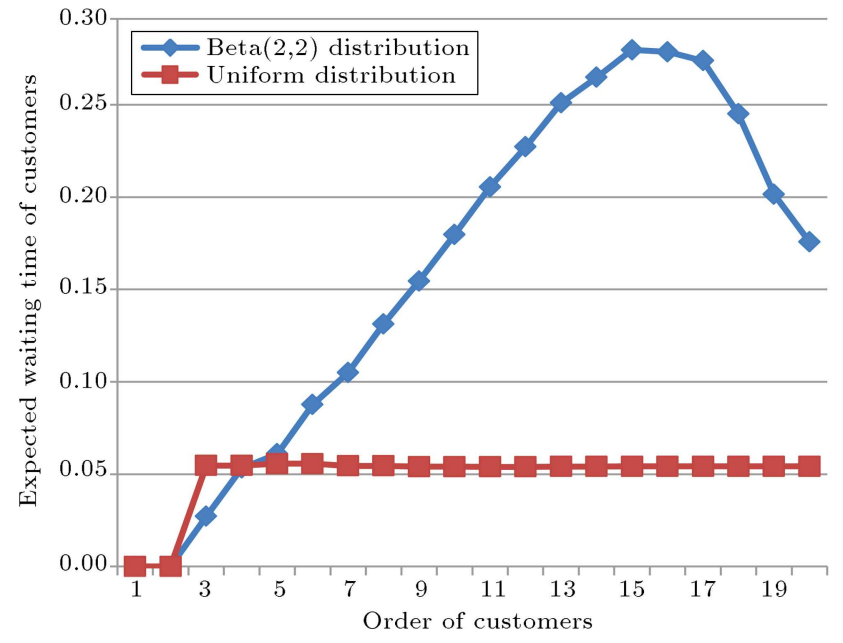

Figure 10. The comparison between uniform and beta arrival distributions for the expected waiting time of each customer based on its arrival order for 20 customers and 6 -unit length time and 2 servers' problem.

\subsection{Cost optimization}

Both the cost of waiting time of customers arriving at the outbound door of the crossdock and the operation and setup costs of the crossdock are significant. These kinds of costs are considered to determine the number of outbound doors and servers. Cost is incurred due to the waiting time of the customers, the fixed costs of an outbound door, and the operation costs of a server. Since the length of time window for service is fixed, it is assumed that the operation cost is fixed. The number of outbound doors is optimized considering all costs. Decreasing the waiting time of customers increases the operation and setup costs, and vice versa. Let us define the following notations:

$C_{w} \quad$ The cost of waiting time of one customer arriving at the outbound door for the unit of time;

$C_{o} \quad$ The total operation and setup costs for one door;

$W_{q} \quad$ The average expected waiting time of customers in the queue.

There is only one decision variable, the number of outbound doors, namely $m$.

The objective function includes two parts: waiting time costs and fixed costs.

The waiting time cost function is descending, and the setup and operation costs of objective functions are ascending in terms of the number of servers. Both costs are approximated using the real case:

$$
\begin{aligned}
& C_{w}=350, \\
& C_{o}=130 .
\end{aligned}
$$

Figures 11 and 12 show the cost function of the problem

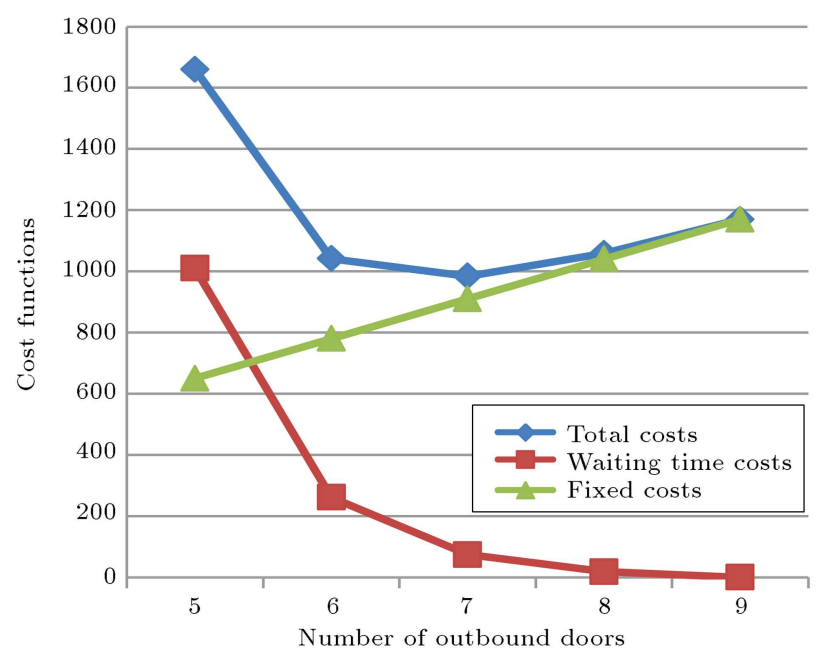

Figure 11. The objective function for the problem with 50 customers, 0.5 unit service time, and 5 -unit length of time window. 
Table 7. Optimum number of doors $m$ with different number of customers and different lengths of time window $l$.

\begin{tabular}{|c|c|c|c|c|c|c|c|c|}
\hline \multirow{2}{*}{$\begin{array}{c}\text { No. of } \\
\text { customer }\end{array}$} & \multicolumn{2}{|c|}{$L=5$} & \multicolumn{2}{|c|}{$L=6$} & \multicolumn{2}{|c|}{$L=8$} & \multicolumn{2}{|c|}{$L=10$} \\
\hline & $m^{*}$ & $F^{*}$ & $m^{*}$ & $F^{*}$ & $\boldsymbol{m}^{*}$ & $F^{*}$ & $m^{*}$ & $F^{*}$ \\
\hline 10 & 2 & 293.12 & 2 & 279.08 & 2 & 267.56 & 1 & 250.96 \\
\hline 15 & 3 & 409.44 & 2 & 364.76 & 2 & 304.28 & 2 & 282.68 \\
\hline 20 & 3 & 480 & 3 & 433.92 & 3 & 402.96 & 2 & 334.88 \\
\hline 25 & 4 & 570.4 & 3 & 527.7 & 3 & 434.1 & 3 & 407.1 \\
\hline 30 & 4 & 669.04 & 4 & 582.64 & 3 & 502.32 & 3 & 436.44 \\
\hline 35 & 5 & 734.42 & 4 & 676.24 & 4 & 559.06 & 3 & 492.06 \\
\hline 40 & 6 & 830.4 & 5 & 726.32 & 4 & 607.84 & 4 & 548.8 \\
\hline 50 & 7 & 983.8 & 6 & 866.4 & 5 & 718.4 & 4 & 633.4 \\
\hline 60 & 8 & 1137.2 & 7 & 1002.88 & 6 & 834 & 5 & 716.96 \\
\hline
\end{tabular}

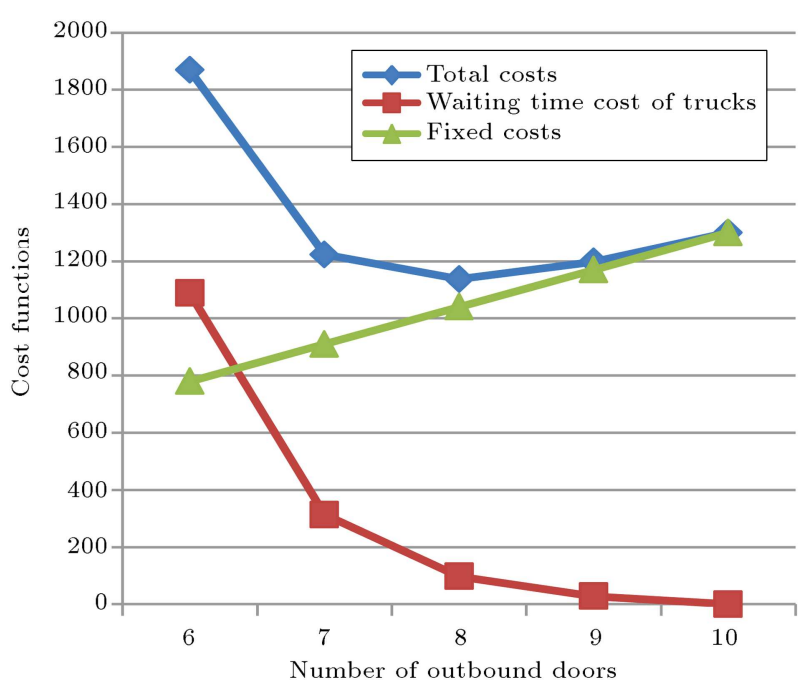

Figure 12. The objective function for the problem with 50 customers, 0.5 unit service time, and 5-unit length of time window.

with 50 and 60 customers, 0.5 unit service time, and 5 -unit length of time window.

It is observed that the total costs of both problems are of the same amount. The total objective function is convex. Therefore, the minimum function can be found easily. The optimum number of doors with the specified parameter is 7 and 8 for 50 and 60 customers, respectively. Table 7 shows the optimum answer for different number of customers and lengths of time window with the number of optimum outbound doors, and $F^{*}$ is the amount of optimum total costs.

\section{Conclusion and discussion}

Crossdocking is a significant subject in supply chain that has earned the spotlight today. Now, this study proposed a new queueing model for the outbound door of a crossdock in a supply chain. The crossdock has $m$ outbound doors with $n$ trucks arriving within a specified time window, according to a uniform distribution and a fixed service time. The expected waiting time of customers was calculated, and the number of outbound doors was optimized based on the minimization of the expected waiting time of customers along with the minimum setup and operation costs of the crossdock. In fact, the queueing system in this study is a finite queue with a finite number of customers that should be served. Since the proposed queueing system is not similar to the classic models, classic methods cannot be used to compute the expected waiting time of customers. Hence, joint conditional distribution of orders statistics was used to calculate the average expected waiting time. Herein, 126 problems with different number of customers, 10-60, different lengths of time window, 5-10, different number of outbound doors, 19 , were solved for the expected waiting time of all customers. Then, the number of servers was optimized based on minimizing the total cost of expected waiting time and setup costs. The application of this study can focus on fruit and vegetable centers of the Iranian cities and distribution companies. Notations in [32] can be extended for such queues by $(n, B, L) / D / m$ as the finite queueing model. The same analysis was conducted because the number of customers and the length of time window were finite, service time was fixed, and arrivals were measured according to any known distribution. Calculating the expected waiting time of customers by the proposed method is the main contribution of the paper.

\section{References}

1. Van Belle, J., Valckenaers, P., and Cattrysse, D. "Cross-docking: State of the art", Omega, 40(6), pp. 827-846 (2012).

2. Kinnear, E. "Is there any magic in cross-docking?", Supply Chain Management: An International Journal, 2(2), pp. 49-52 (1997).

3. Shiguemoto, A.L., Cavalcante Netto, U.S., and Bauab, G.H.S. "An efficient hybrid meta-heuristic for a cross- 
docking system with temporary storage", International Journal of Production Research, 52(4), pp. 1231-1239 (2014).

4. Yu, W. and Egbelu, P.J. "Scheduling of inbound and outbound trucks in cross docking systems with temporary storage", European Journal of Operational Research, 184(1), pp. 377-396 (2008).

5. Arabani, A.B., Ghomi, S.F., and Zandieh, M. "Metaheuristics implementation for scheduling of trucks in a cross-docking system with temporary storage", $E x$ pert Systems with Applications, 38(3), pp. 1964-1979 (2011).

6. Miao, Z., Yang, F., and Fu, K. "Transshipment problem with penalty in crossdocking distribution networks", 6th International Conference on Service Systems and Service Management, pp. 280-285 (2009).

7. Miao, Z., Fu, K., Fei, Q., and Wang, F. "Meta-heuristic algorithm for the transshipment problem with fixed transportation schedules", In New Frontiers in Applied Artificial Intelligence, pp. 601-610, Springer (2008).

8. Marjani, M.R., Husseini, S.M.M., and Karimi, B. "Bi-objective heuristics for multi-item freights distribution planning problem in crossdocking networks", The International Journal of Advanced Manufacturing Technology, 58(9-12), pp. 1201-1216 (2012).

9. Shi, W., Liu, Z., Shang, J., and Cui, Y. "Multicriteria robust design of a JIT-based cross-docking distribution center for an auto parts supply chain", European Journal of Operational Research, 229(3), pp. 695-706 (2013).

10. Bartholdi, J.J. and Gue, K.R. "The best shape for a crossdock", Transportation Science, 38(2), pp. 235-244 (2004).

11. Hauser, K. and Chung, C.H. "Genetic algorithms for layout optimization in crossdocking operations of a manufacturing plant", International Journal of Production Research, 44(21), pp. 4663-4680 (2006).

12. Vis, I.F. and Roodbergen, K.J. "Layout and control policies for cross docking operations", Computers \& Industrial Engineering, 61(4), pp. 911-919 (2011).

13. Ladier, A.-L. and Alpan, G. "Cross-docking operations: Current research versus industry practice", Omega, 62, pp.145-162 (2015).

14. Lim, A., Ma, H., and Miao, Z. "Truck dock assignment problem with time windows and capacity constraint in transshipment network through crossdocks", In Computational Science and Its Applications-ICCSA 2006, pp. 688-697, Springer (2006).

15. Gelareh, S., Monemi, R.N., Semet, F., and Goncalves, G. "A branch-and-cut algorithm for the truck dock assignment problem with operational time constraints", European Journal of Operational Research, 249(3), pp. 1144-1152 (2016).

16. Boysen, N. and Fliedner, M. "Cross dock scheduling: Classification, literature review and research agenda", Omega, 38(6), pp. 413-422 (2010).
17. Ladier, A.-L. and Alpan, G. "Crossdock truck scheduling with time windows: Earliness, tardiness and storage policies", Journal of Intelligent Manufacturing, 29(3), pp. 569-583 (2014).

18. Ma, H., Miao, Z., Lim, A., and Rodrigues, B. "Crossdocking distribution networks with setup cost and time window constraint", Omega, 39(1), pp. 64-72 (2011).

19. Chen, P., Guo, Y., Lim, A., and Rodrigues, B. "Multiple crossdocks with inventory and time windows", Computers \& Operations Research, 33(1), pp. 43-63 (2006).

20. Lim, A., Miao, Z., Rodrigues, B., and Xu, Z. "Transshipment through crossdocks with inventory and time windows", Naval Research Logistics (NRL), 52(8), pp. 724-733 (2005).

21. Walha, F., Chaabane, S., Bekrar, A., and Loukil, T. "The cross docking under uncertainty: State of the art", 2014 International Conference on Advanced Logistics and Transport (ICALT), pp. 330-335 (2014).

22. Konur, D. and Golias, M.M. "Cost-stable truck scheduling at a cross-dock facility with unknown truck arrivals: A meta-heuristic approach", Transportation Research Part E: Logistics and Transportation Review, 49(1), pp. 71-91 (2013).

23. Konur, D. and Golias, M.M. "Analysis of different approaches to cross-dock truck scheduling with truck arrival time uncertainty", Computers \& Industrial Engineering, 65(4), pp. 663-672 (2013).

24. Larbi, R., Alpan, G., Baptiste, P., and Penz, B. "Scheduling cross docking operations under full, partial and no information on inbound arrivals", Computers \& Operations Research, 38(6), pp. 889-900 (2011).

25. Vis, I.F. and Roodbergen, K.J. "Positioning of goods in a cross-docking environment", Computers \& Industrial Engineering, 54(3), pp. 677-689 (2008).

26. Sathasivan, K. "Optimizing cross-dock operations under uncertainty", Ph.D. Dissertation, The University of Texas at Austin (2011).

27. Acar, K., Yalcin, A., and Yankov, D. "Robust door assignment in less-than-truckload terminals", Computers \& Industrial Engineering, 63(4), pp. 729-738 (2012).

28. Louchard, G. "Large finite population queueing systems. The single-server model", Stochastic Processes and Their Applications, 53(1), pp. 117-145 (1994).

29. Jain, R., Juneja, S., and Shimkin, N. "The concert queueing game: to wait or to be late", Discrete Event Dynamic Systems, 21(1), pp. 103-138 (2011).

30. Honnappa, H., Jain, R., and Ward, A.R. "A queueing model with independent arrivals, and its fluid and diffusion limits", Queueing Systems, 80(1-2), pp. 71103 (2014).

31. Chen, G., Govindan, K., Yang, Z.Z., Choi, T.M., and Jiang, L. "Terminal appointment system design by non-stationary $\mathrm{M}(\mathrm{t}) / \mathrm{E} \mathrm{k} / \mathrm{c}(\mathrm{t})$ queueing model and genetic algorithm", International Journal of Production Economics, 146(2), pp. 694-703 (2013). 
32. Motaghedi-Larijani, A. and Aminnayeri, M. "Optimizing the admission time of outbound trucks entering a cross-dock with uniform arrival time by considering a queuing model", Engineering Optimization, 49(3), pp. 466-480 (2016).

\section{Biographies}

Arash Motaghedi-Larijani is born in 1986. He obtained his BSc degree in Industrial Engineering from Khaje Nasir University of Technology in 2008. He received his MSc degree in Industrial Engineering from University of Science and Technology in 2011. He is $\mathrm{PhD}$ Candidate at the Amirkabir University of Technology at the moment. He has 5 ISI and ISC journal papers and 4 conference papers. His thesis is on determining the number of crossdock under stochastic parameters.

Majid Aminnayer is born in 1951. He received his BSc and MSc degrees in Mathematics and Statistics from Pahlavi University in 1973 and 1975, respectively. Then, he received another MSc degree in statistics from Iowa State University, USA in 1979. He continued toward his $\mathrm{PhD}$ and received his degree as a double major in Statistics and Industrial Engineering from Iowa State University in 1981. He has over 120 published journal and conference papers; at the moment, he is an Associated Professor at Amirkabir University of Technology. 